\title{
The relationships between isometric muscle strength and respiratory functions of the Turkish National Paralympic Goalball Team
}

\author{
Aydın Balcı', Bihter Akınoğlu ${ }^{23, *}$, Tuğba Kocahan ${ }^{3}$, Adnan Hasanoğlu ${ }^{3}$ \\ 'Department of Sports Medicine, Yenimahalle Training and Research Hospital, Yildirim Beyazit University, Ankara, Turkey \\ ${ }^{2}$ Department of Physiotherapy and Rehabilitation, Faculty of Health Sciences, Ankara Yıldırım Beyazıt University, Ankara, Turkey \\ ${ }^{3}$ Center of Athlete Training and Health Research, Ankara, Turkey
}

Goalball is a unique sport for only blind and visually disabled people to prevent physical inactivity and its harmful consequences. Determining the profile of physical fitness parameters and their relationship is crucial for all sports discipline. The purpose of the study is to determine the characteristics and the relationship between isometric muscle strength and respiratory functions. A total of 14 (10 female, four male athletes) goalball athletes were included in the study. Upper-extremity, lower-extremity and trunk isometric muscle strength and pulmonary function tests measurements were performed to the athletes on two different days. The relationship between parameters was evaluated by Spearman correlation test. Strength and pulmonary function parameters were higher in male athletes $(P<0.05)$. A medium/strong/very strong correlation was found between respiratory function and upper extremi- ty isometric muscle strength $(r=0.529-0.917, P<0.05)$. A moderate/ strong correlation was found between lower extremity isometric muscle strength and respiratory function $(r=0.534-0.867, P<0.05)$. A moderate correlation was found between trunk isometric muscle strength and respiratory function $(r=0.538-0.640, P<0.05)$. It was seen that respiratory functions were associated with upper-lower extremity and trunk muscle strength. With this result, the idea arises that strength exercises can affect the improvement of respiratory function in individuals with disabilities, which is very important for both overall health and sports performance.

Keywords: Goalball, Muscle strength, Respiratory functions

\section{INTRODUCTION}

The participation of disabled people in sports has significantly increased in recent years. In many branches, competitions are organized for disabled athletes from amateur to elite level. Increasing the participation of people with disabilities in sports is important both because of the protective effect of physical activity from chronic diseases and because it improves the self-confidence and social relations of these individuals (Akınoğlu and Kocahan, 2017; Blauwet and Willick, 2012). Paralympic games have created awareness about the participation of disabled people in these sports. In these games, there are many sports branches that are rearranged with special rules for the disabled. Goalball is one of these sports branches and increases the participation of visually impaired individuals in physical activity and has a positive effect on physical fitness parameters (Caliskan et al., 2011).

Muscle strength is a critical physical fitness parameter that affects both daily life activities and sports performance (Prieske et al., 2016). It has a significant effect on activities such as jumping (McGuigan et al., 2010), sprint (Peterson et al., 2006), and throwing (Carter et al., 2007). It also has an important effect in preventing sports injuries (Niemuth, 2007).

Respiratory functions determine general health status and are an important physical fitness parameter such as muscle strength (Sener et al., 2016). There are also studies showing that respiratory functions have an effect on sports performance (Boutellier et al.,
${ }^{*}$ Corresponding author: Bihter Akınoğlu (i) https://orcid.org/0000-0002-8214-7895 Department of Physiotherapy and Rehabilitation, Faculty of Health Sciences, Ankara Yildırım Beyazıt University, Ankara, Turkey Email: rgkardelen@yahoo.com

Received: November 19, 2020 / Accepted: December 11, 2020
This is an Open Access article distributed under the terms of the Creative Commons Attribution Non-Commercial License (https://creativecommons.org/licenses/by-nc/4.0/) which permits unrestricted non-commercial use, distribution, and reproduction in any medium, provided the original work is properly cited. 
1992; Gian et al., 2019). Although it is known that the skeletal muscles do not take part in respiration during normal breathing, it is thought that the trunk and extremity muscles support breathing with the increase in exercise intensity (Lee et al., 2018; Liu et al., 2019).

The relationship between muscle strength and respiratory functions has been investigated in previous studies. Some of these studies have shown that there is a relationship between the two parameters (Bae et al., 2015; Kim, 2018; Liu et al., 2019); however, according to the authors' knowledge, there is no study investigating the relationship between more than one muscle group and respiratory functions in visually impaired athletes.

In the light of this information, with the hypothesis that there will be a relationship between isometric muscle strength and respiratory functions, the aim of the study is to determine the relationship between upper-lower extremity and trunk isometric muscle strength and respiratory functions of goalball athletes.

\section{MATERIALS AND METHODS}

\section{Participants}

A total of 14 Paralympic goalball players (10 female and four male athletes), who were in the camp with their national teams, were included in the study. The athletes were given detailed information about the study. Verbal and written consent was obtained from the athletes and their representatives, and also the athletes' sickness and injury history were asked. Physical examinations were performed by a sports medicine specialist. Those with active disease and injury were not included in the study. Ethical approval was obtained from the Ankara Yıldırım Beyazit University ethics committee for the study with the number of 2020/209:26, and the study was conducted in accordance with the 2008 Principles of the Helsinki Declaration.

\section{Study procedure}

Athletes who agreed to participate in the study and whose consent was obtained were included in the study. The demographic characteristics of the athletes were recorded on the first day. The upper-lower extremity and trunk isometric muscle strength of the athletes were evaluated on the same day. The respiratory functions of the athletes were evaluated on the second day.

\section{Isometric muscle strength measurement of upper-upper extremity and trunk}

The isometric muscle strength of the athletes was evaluated with the DIERS-Myoline Isometric Muscle Strength Analysis System (DIERS International GmbH, Schlangenbad, Germany). Within this system, shoulder internal/external rotation, elbow flexion/extension, trunk flexion/extension, trunk lateral flexion, trunk rotation, hip flexion/extension, and hip abduction/adduction muscle strength were measured.

\section{Respiratory functions evaluation}

The respiratory functions of the athletes were evaluated with a digital spirometer (Pony FX, Cosmed, Albano Laziale, Italy). Before the evaluation, the athletes were informed about the test. It was ensured that the athletes did not eat in the last $2 \mathrm{hr}$ and did rest $15 \mathrm{~min}$ before the evaluation. Tests were performed in a sitting position. During the evaluation, the noses of the athletes were closed with the nose clip of the device. At the same time, the athletes were asked to hold the mouthpiece tightly with their lips to prevent air from escaping around the mouthpiece of the device. Before the evaluation started, it was ensured that the athletes were adapted to the device. Each measurement was repeated three times, and the best result was recorded for statistical analysis (Akınoğlu et al., 2019; Graham et al., 2019).

Functional vital capacity was measured to determine the respiratory function values of the athletes. During the measurement, the athletes were first asked to take a breath as deep as they could and then completely evacuate the air from their lungs as vigorously and quickly as possible. As a result of the test; forced vital capacity (FVC), forced expiratory volume in $1 \mathrm{sec}\left(\mathrm{FEV}_{1}\right)$, and mean forced expiratory flow between the $25 \%$ and $75 \%$ of the FVC $\left(\mathrm{FEF}_{25 \%-75 \%)}\right)$ were obtained for statistical analysis.

\section{Statistical analysis}

Statistics of the study were made using IBM SPSS Statistics ver. 20.0 (IBM Co., Armonk, NY, USA). Visual (histogram, probability charts) and analytical (Kolmogorov-Smirnov test) methods were used to define whether the obtained data were normally distributed. All data were analyzed by Mann-Whitney $U$-test to determine gender differences. The relationship between the upperlower extremity and trunk isometric muscle strength with respiratory functions was determined by the Spearman correlation test. The level of correlation was classified as negligible $(r=0-0.3)$, low $(r=0.31-0.50)$, moderate $(r=0.51-0.70)$, strong $(r=0.71-0.90)$, and very strong $(r=0.91-1.0)$ (Mukaka, 2012). Statistical significance level was accepted as $P<0.05$. 


\section{RESULTS}

The age, height, body weight, isometric muscle strength, and respiratory function values of the athletes and the comparison of these values according to gender are shown in Table 1 . There was no significant difference between both elbow extension isometric muscle strength, left elbow flexion isometric muscle strength, and both hip flexion isometric muscle strength values $(P>0.05)$. All values except these values were found higher in male than female athletes $(P<0.05)$.

The relationship between upper extremity isometric muscle strength and respiratory functions of athletes is given in Table 2. A moderate-strong-very strong correlation was found between both elbow flexion, internal and external rotation of both shoulders, and respiratory functions $(r=0.529-0.917, P<0.05)$. No statistically significant correlation was found between both elbow extension isometric muscle strength and respiratory functions $(P>0.05)$.

The relationship between lower extremity isometric muscle strength and respiratory functions of athletes is given in Table 3. A moderate-strong correlation was found between isometric muscle strength in both hip extension, abduction, and adduction and respiratory functions $(r=0.534-0.867, P<0.05)$. No statistically significant correlation was found between both hip flexion isometric muscle strength and respiratory functions $(P>0.05)$.

The relationship between trunk isometric muscle strength and respiratory functions of athletes is given in Table 4. A moderate

Table 1. Age, height, body weight, isometric muscle strength, and respiratory function test values of athletes

\begin{tabular}{|c|c|c|c|c|c|c|c|}
\hline \multirow{2}{*}{ Variable } & \multicolumn{3}{|c|}{ Female $(n=10)$} & \multicolumn{3}{|c|}{ Male $(n=4)$} & \multirow{2}{*}{$P$-value ${ }^{*}$} \\
\hline & Mean \pm SD & Median & Range & Mean \pm SD & Median & Range & \\
\hline Age (yr) & $19.9 \pm 3.51$ & 19.00 & $15.00-25.00$ & $29 \pm 3.56$ & 29.50 & $25.00-32.00$ & 0.007 \\
\hline Height (cm) & $159.32 \pm 4.57$ & 158.00 & 156.00-172.00 & $186.25 \pm 4.19$ & 185.50 & 182.00-192.00 & 0.004 \\
\hline Body weight (kg) & $57.58 \pm 6.45$ & 55.95 & 48.7.-69.40 & $89.05 \pm 11.34$ & 86.50 & 78.2-105.00 & 0.005 \\
\hline Left elbow extension (N) & $204.8 \pm 91.54$ & 211.00 & $95.00-401.00$ & $300.25 \pm 122.04$ & 310.00 & $142.00-439.00$ & 0.089 \\
\hline Right elbow extension (N) & $179.5 \pm 61.29$ & 179.50 & $93.00-269.00$ & $247.25 \pm 100.37$ & 293.00 & $97.00-306.00$ & 0.119 \\
\hline Left elbow flexion (N) & $250.6 \pm 25.39$ & 253.00 & 210.00-281.00 & $421.25 \pm 116.39$ & 436.00 & $266.00-547.00$ & 0.023 \\
\hline Right elbow flexion (N) & $282.9 \pm 27.15$ & 282.50 & $237.00-338.00$ & $487 \pm 181.86$ & 529.00 & $253.00-637.00$ & 0.103 \\
\hline Left shoulder ER (N) & $154 \pm 28.87$ & 149.50 & 115.00-197.00 & $374 \pm 102.66$ & 388.00 & $253.00-467.00$ & 0.005 \\
\hline Right shoulder ER (N) & $154.5 \pm 26.8$ & 158.50 & 104.00-187.00 & $375.75 \pm 114.82$ & 368.00 & $267.00-500.00$ & 0.005 \\
\hline Left shoulder IR (N) & $233.7 \pm 46.89$ & 228.50 & $170.00-316.00$ & $538.5 \pm 54.95$ & 527.00 & 486.00-614.00 & 0.005 \\
\hline Right shoulder IR (N) & $226.2 \pm 44.51$ & 215.00 & 167.00-287.00 & $536 \pm 24.71$ & 531.00 & $512.00-570.00$ & 0.005 \\
\hline Trunk extension (N) & $143.7 \pm 87.33$ & 97.50 & $66.00-309.00$ & $388.5 \pm 161.76$ & 377.00 & $215.00-585.00$ & 0.016 \\
\hline Trunk flexion (N) & $89.9 \pm 63.81$ & 72.50 & $31.00-262.00$ & $160.5 \pm 54.31$ & 172.00 & 93.00-205.00 & 0.034 \\
\hline Trunk left lateral flexion (N) & $263.3 \pm 65.98$ & 262.50 & $177.00-369.00$ & $498.5 \pm 171.89$ & 575.00 & $243.00-601.00$ & 0.034 \\
\hline Trunk right lateral flexion (N) & $268.7 \pm 85.51$ & 242.50 & $146.00-420.00$ & $531.75 \pm 219.14$ & 508.00 & $300.00-811.00$ & 0.011 \\
\hline Trunk left rotation (N) & $256.4 \pm 70.06$ & 277.50 & $146.00-330.00$ & $687.75 \pm 357.97$ & 581.00 & $387.00-1,202.00$ & 0.005 \\
\hline Trunk right rotation (N) & $252.8 \pm 92.76$ & 280.50 & $81.00-362.00$ & $553.5 \pm 277.46$ & 446.00 & $367.00-955.00$ & 0.005 \\
\hline Left leg extension (N) & $355.8 \pm 69.22$ & 328.50 & $270.00-479.00$ & $619 \pm 112.52$ & 648.50 & 470.00-709.00 & 0.007 \\
\hline Right leg extension (N) & $350.3 \pm 81.47$ & 318.00 & $259.00-531.00$ & $639 \pm 116.54$ & 643.00 & 497.00-773.00 & 0.007 \\
\hline Left leg flexion (N) & $102.8 \pm 49.39$ & 107.00 & $53.00-217.00$ & $136.25 \pm 35.37$ & 150.00 & 84.00-161.00 & 0.119 \\
\hline Right leg flexion (N) & $121.2 \pm 60.29$ & 124.50 & $51.00-260.00$ & $163.25 \pm 59.89$ & 154.50 & 100.00-244.00 & 0.119 \\
\hline Left leg abduction (N) & $526.3 \pm 132.65$ & 503.50 & $33.007-777.00$ & $1,331.75 \pm 206.08$ & 1,398.50 & $1,036.00-1,494.00$ & 0.005 \\
\hline Right leg abduction (N) & $523.2 \pm 96.92$ & 497.50 & 410.00-702.00 & $1,255.5 \pm 132.29$ & $1,265.50$ & $1,087.00-1,404.00$ & 0.005 \\
\hline Left leg adduction (N) & $712.5 \pm 155.21$ & 720.00 & $440.00-944.00$ & $1,342.5 \pm 120.96$ & $1,313.00$ & $1,231.00-1,513.00$ & 0.005 \\
\hline Right leg adduction (N) & $719.8 \pm 172.74$ & 755.00 & 420.00-968.00 & $1,424 \pm 63.73$ & $1,405.50$ & $1,369.00-1,516.00$ & 0.005 \\
\hline $\mathrm{FVC}(\mathrm{L})$ & $3.78 \pm 0.56$ & 3.77 & $2.93-4.91$ & $5.96 \pm 0.18$ & 5.97 & $5.73-6.16$ & 0.005 \\
\hline $\mathrm{FEV}_{1}(\mathrm{~L})$ & $3.22 \pm 0.38$ & 3.18 & $2.79-4.10$ & $4.79 \pm 0.36$ & 4.85 & $4.30-5.16$ & 0.005 \\
\hline $\mathrm{FEF}_{25 \%-75 \%}(\mathrm{~L} / \mathrm{sec})$ & $3.32 \pm 0.67$ & 3.40 & $2.10-4.13$ & $4.62 \pm 1.15$ & 4.91 & $3.08-5.58$ & 0.066 \\
\hline
\end{tabular}

SD, standard deviation; N, Newton; ER, external rotation; IR, internal rotation; FVC, forced vital capacity; FEV 1 , forced expiratory volume in 1 sec; FEF $25 \%-75 \%$, mean forced expiratory flow between the $25 \%$ and $75 \%$ of the FVC.

*Mann-Whitney U-test. 
Table 2. Relationship between upper extremity isometric muscle strength and respiratory function tests of all athletes

\begin{tabular}{|c|c|c|c|c|c|c|c|c|}
\hline \multirow{2}{*}{$\begin{array}{l}\text { Respiratory } \\
\text { function test }\end{array}$} & \multicolumn{8}{|c|}{ Upper extremity isometric muscle strength } \\
\hline & $\begin{array}{l}\text { Left elbow } \\
\text { extension (N) }\end{array}$ & $\begin{array}{l}\text { Right elbow } \\
\text { extension (N) }\end{array}$ & $\begin{array}{l}\text { Left elbow } \\
\text { flexion (N) }\end{array}$ & $\begin{array}{l}\text { Right elbow } \\
\text { flexion (N) }\end{array}$ & $\begin{array}{l}\text { Left shoulder } \\
\text { ER (N) }\end{array}$ & $\begin{array}{c}\text { Right shoulder } \\
\text { ER (N) }\end{array}$ & $\begin{array}{l}\text { Left shoulder } \\
\qquad \mathbb{R}(\mathrm{N})\end{array}$ & $\begin{array}{c}\text { Right shoulder } \\
\text { IR (N) }\end{array}$ \\
\hline \multicolumn{9}{|l|}{$\mathrm{FVC}(\mathrm{L})$} \\
\hline Cor* & 0.401 & 0.401 & 0.670 & 0.529 & 0.733 & 0.790 & $0.847^{* * *}$ & $0.813^{* * *}$ \\
\hline$P$-value & 0.155 & 0.155 & 0.009 & 0.052 & 0.003 & 0.001 & 0.000 & 0.000 \\
\hline \multicolumn{9}{|l|}{$\mathrm{FEV}_{1}(\mathrm{~L})$} \\
\hline Cor* & 0.402 & 0.426 & 0.776 & 0.693 & 0.728 & 0.803 & $0.917^{* * *}$ & $0.815^{* * *}$ \\
\hline$P$-value & 0.154 & 0.129 & 0.001 & 0.006 & 0.003 & 0.001 & 0.000 & 0.000 \\
\hline \multicolumn{9}{|l|}{$\mathrm{FEF}_{25 \%-75 \%}(\mathrm{~L} / \mathrm{sec})$} \\
\hline Cor* & 0.350 & 0.398 & 0.650 & 0.774 & 0.538 & 0.582 & $0.604^{*}$ & 0.433 \\
\hline$P$-value & 0.220 & 0.158 & 0.012 & 0.001 & 0.047 & 0.029 & 0.022 & 0.122 \\
\hline
\end{tabular}

Cor, Spearman correlation; $\mathrm{FVC}$, forced vital capacity; $\mathrm{FEV}_{1}$, forced expiratory volume in $1 \mathrm{sec}$; $\mathrm{FEF}_{25 \%}-75 \%$, mean forced expiratory flow between the $25 \%$ and $75 \%$ of the $\mathrm{FVC}$; $\mathrm{N}$, Newton; ER, external rotation; IR, internal rotation.

${ }^{*} P<0.05{ }^{* * *} P<0.001$.

Table 3. Relationship between trunk isometric muscle strength and respiratory function tests of all athletes

\begin{tabular}{|c|c|c|c|c|c|c|}
\hline \multirow{2}{*}{ Respiratory function test } & \multicolumn{6}{|c|}{ Trunk isometric muscle strength } \\
\hline & Trunk extension (N) & Trunk flexion (N) & Left lateral flexion (N) & Right lateral flexion (N) & Left rotation (N) & Right rotation (N) \\
\hline \multicolumn{7}{|l|}{$\mathrm{FVC}(\mathrm{L})$} \\
\hline Cor* & 0.334 & 0.400 & 0.405 & $0.576^{*}$ & $0.576^{*}$ & $0.603^{*}$ \\
\hline$P$-value & 0.243 & 0.156 & 0.151 & 0.031 & 0.031 & 0.022 \\
\hline \multicolumn{7}{|l|}{$\mathrm{FEV}_{1}(\mathrm{~L})$} \\
\hline Cor* & 0.431 & 0.354 & 0.493 & $0.607^{*}$ & $0.634^{*}$ & $0.640^{*}$ \\
\hline$P$-value & 0.124 & 0.214 & 0.073 & 0.021 & 0.015 & 0.014 \\
\hline \multicolumn{7}{|l|}{$\mathrm{FEF}_{25 \%-75 \%}(\mathrm{~L} / \mathrm{sec})$} \\
\hline Cor* & 0.455 & 0.068 & $0.538 *$ & $0.569^{*}$ & $0.556^{*}$ & 0.455 \\
\hline$P$-value & 0.102 & 0.817 & 0.047 & 0.034 & 0.039 & 0.102 \\
\hline
\end{tabular}

Cor, Spearman correlation; FVC, forced vital capacity; $F E V_{1}$, forced expiratory volume in 1 sec; $\mathrm{FEF}_{25 \%}-75 \%$, mean forced expiratory flow between the $25 \%$ and $75 \%$ of the $\mathrm{FVC}$; $\mathrm{N}$, Newton; ER, external rotation; IR, internal rotation.

${ }^{*} P<0.05$.

Table 4. Relationship between lower extremity isometric muscle strength and respiratory function tests of all athletes

\begin{tabular}{|c|c|c|c|c|c|c|c|c|}
\hline \multirow{2}{*}{$\begin{array}{l}\text { Respiratory } \\
\text { function test }\end{array}$} & \multicolumn{8}{|c|}{ Lower extremity isometric muscle strength } \\
\hline & $\begin{array}{c}\text { Left leg } \\
\text { extension (N) }\end{array}$ & $\begin{array}{c}\text { Right leg } \\
\text { extension (N) }\end{array}$ & $\begin{array}{l}\text { Left leg } \\
\text { flexion (N) }\end{array}$ & $\begin{array}{l}\text { Right leg } \\
\text { flexion (N) }\end{array}$ & $\begin{array}{c}\text { Left leg } \\
\text { abduction (N) }\end{array}$ & $\begin{array}{c}\text { Right leg } \\
\text { abduction (N) }\end{array}$ & $\begin{array}{l}\text { Left leg } \\
\text { adduction (N) }\end{array}$ & $\begin{array}{l}\text { Right leg } \\
\text { adduction (N) }\end{array}$ \\
\hline \multicolumn{9}{|l|}{$\mathrm{FVC}(\mathrm{L})$} \\
\hline Cor* & 0.759 & 0.598 & 0.097 & 0.122 & 0.763 & 0.707 & 0.739 & $0.829^{* * *}$ \\
\hline$P$-value & 0.002 & 0.024 & 0.742 & 0.677 & 0.001 & 0.005 & 0.003 & 0.000 \\
\hline \multicolumn{9}{|l|}{$\mathrm{FEV}_{1}(\mathrm{~L})$} \\
\hline Cor $^{*}$ & 0.774 & 0.702 & 0.170 & 0.183 & 0.832 & 0.770 & 0.768 & $0.867^{* * *}$ \\
\hline$P$-value & 0.001 & 0.005 & 0.562 & 0.532 & 0.000 & 0.001 & 0.001 & 0.000 \\
\hline \multicolumn{9}{|l|}{$\mathrm{FEF}_{25 \%-75 \%}(\mathrm{~L} / \mathrm{sec})$} \\
\hline Cor* $^{*}$ & 0.534 & 0.684 & 0.119 & 0.081 & 0.534 & 0.642 & 0.464 & 0.455 \\
\hline$P$-value & 0.049 & 0.007 & 0.686 & 0.782 & 0.049 & 0.013 & 0.095 & 0.102 \\
\hline
\end{tabular}

Cor, Spearman correlation; FVC, forced vital capacity; FEV , forced expiratory volume in 1 sec; $\mathrm{FEF}_{25 \%}-75 \%$, mean forced expiratory flow between the $25 \%$ and $75 \%$ of the $\mathrm{FVC}$; $\mathrm{N}$, Newton; ER, external rotation; IR, internal rotation.

${ }^{*} P<0.05$. ${ }^{* *} P<0.001$. 
correlation was found between trunk right-left rotation and rightleft lateral flexion isometric muscle strength and respiratory functions $(r=0.538-640 ; P<0.05)$. No statistically significant correlation was found between trunk flexion and extension isometric muscle strength and respiratory functions $(P>0.05)$.

\section{DISCUSSION}

This study was carried out to determine the relationship between upper-lower extremity and trunk isometric muscle strength with respiratory functions of goalball athletes, with the hypothesis that there would be a relationship between isometric muscle strength and respiratory functions. To the results of the study, a relationship was found between upper-lower extremity and trunk isometric muscle strength and respiratory functions of goalball athletes.

Muscle strength is one of the important parameters affecting sports performance (Suchomel et al., 2016). There are also many factors that can affect muscle strength (Tsolakis et al., 2020), and gender emerges as one of the most important factors affecting muscle strength (Tsolakis et al., 2020). In the literature, it is stated that men have more muscle strength than women (Sinaki et al., 2001), and this situation is similar in individuals who do sports (Tsolakis et al., 2020). According to the authors' knowledge, there are no studies comparing muscle strength in male and female athletes with disabilities. In this study according to gender, isometric muscle strength was found to be higher in male athletes compared to female athletes except for elbow extension and leg flexion values. Similarly, respiratory functions also affect sports performance (Salinero et al., 2016), and respiratory functions also differ between genders (Stavrou et al., 2018). In the literature, it is stated that men have more pulmonary function parameters than women and male athletes' pulmonary function is better than female athletes (Quanjer et al., 2012; Stavrou et al., 2018). However, we did not find any study comparing respiratory functions between genders in individuals with disabilities who do sports. Similarly, respiratory function values were higher in male athletes than female athletes. This is a rare study in the field comparing muscle strength and respiratory function between genders in athletes with visual disability. This result is consistent with the literature knowledge that muscle strength and respiratory functions are higher in male (Barber-Westin et al., 2006; Danneskiold-Samsøe et al., 2009; Quanjer et al., 2012). These results of our study may reveal that visually impaired individuals will have gender differences similar to healthy individuals.

There are many studies investigating the relationship between peripheral muscle strength and respiratory functions (Akınoğlu et al., 2019; Ulubay et al., 2017). In these studies, it is stated that as peripheral muscle strength increases, respiratory functions increase (Akınoğlu et al., 2019) and peripheral muscle strength may be an indicator of respiratory functions in sick individuals (Ulubay et al., 2017). In addition, it has been determined that there is a relationship between upper extremity muscles strength and respiratory functions (Liu et al., 2019) and strength training for upper extremity muscles increases respiratory functions in disabled individuals (Shin and Kim, 2017). In this study, when the relationship between upper extremity isometric muscle strength and respiratory functions was examined, it was found that there was a moderate/strong/very strong relationship between elbow flexion, shoulder internal and external rotation muscle strength with respiratory functions. It is thought that upper extremity muscles may contribute to respiratory functions by changing the chest volume (Liu et al., 2019). The results of the present study are in line with the literature knowledge that also in athletes with visual impairment upper extremity muscles are associated with respiratory functions (Sillanpää et al., 2014; Son et al., 2018).

The diaphragm muscle is the most important contractile district used for breathing (Bordoni et al., 2020). The diaphragm muscle is involved in core stabilization together with trunk flexor, extensor, lateral flexor, and rotator muscles. For this reason, a relationship between trunk muscles and respiratory functions is an expected condition. In this study, a moderate relationship was found between trunk lateral flexor and rotator isometric muscle strength and respiratory functions. However, this relationship was not observed between trunk flexion and extension isometric muscle strength with respiratory functions. There are studies in the literature that have determined a relationship between trunk muscle performance and respiratory functions, and these studies have shown that trunk flexion muscles are related to respiratory functions (Cavaggioni et al., 2015). Measuring the trunk flexor and extensor muscle strength of athletes in sitting position in our study, and the fact that these measurements were made for core endurance in different positions in the literature may be the reason for the difference presenting this relation in our study (Cavaggioni et al., 2015; Tong et al., 2014).

Just like in the upper extremity, the relationship between lower extremity muscle strength and functional status and respiratory functions has been the subject of many studies (Akınoğlu et al., 2019; Padkao and Boonla, 2020; Singer et al., 2011). In a study conducted with athletes, authors indicated that the knee flexor and extensor muscle strength, respiratory function and respiratory muscle strength develop parallel to each other and the codevelop- 
ment of these parameters together with special exercises to increase respiratory muscle strength will improve the performance of the athletes (Akınoğlu et al., 2019). According to the current study of the relationship between lower extremity isometric muscle strength and respiratory functions, a moderate and strong relationship was found between hip extension, hip abduction, and hip adduction and respiratory functions. In this respect, this study is compatible with other studies in the literature.

Due to the small number of participants, it was not possible to evaluate the male and female athletes separately and to analyze the relationship between strength parameters and respiratory functions by linear regression. Besides, the fact that the study is a cross-sectional study does not show a cause-effect relationship. These situations can be considered as the limitations of the study. On the other hand, the fact that the study was conducted on goalball athletes with both extremities and trunk isometric muscle strength evaluations caused the present study to differ from previous studies in the literature.

It is stated in the literature that physical fitness parameters of disabled individuals are lower than their healthy peers (Wouters et al., 2020). Consequently, it was seen that respiratory functions were related to upper-lower extremity and trunk muscle strength in athletes with visual impairment. Considering that the physical fitness parameters of individuals with disability are lower than healthy individuals (Wouters et al., 2020), it is thought that strength exercises of the upper-lower extremities and trunk may have an effect on the improvement of respiratory functions, which is important for both general health and sports performance in athletes with visual impairment. The results of our study reveal the importance of doing sports in line with training sciences also in individuals with visual impairment and considering physiological parameters to increase sports performance in these individuals.

\section{CONFLICT OF INTEREST}

No potential conflict of interest relevant to this article was reported.

\section{ACKNOWLEDGMENTS}

The authors received no financial support for this article.

\section{REFERENCES}

Aknnoğlu B, Kocahan T. Characteristics of upper extremity's muscle strength in Turkish national wheelchair basketball players team. J Exerc Rehabil 2017;13:62-67.

Akınoğlu B, Kocahan T, Özkan T. The relationship between peripheral muscle strength and respiratory function and respiratory muscle strength in athletes. J Exerc Rehabil 2019;15:44-49.

Bae JY, Jang KS, Kang S, Han DH, Yang W, Shin KO. Correlation between basic physical fitness and pulmonary function in Korean children and adolescents: a cross-sectional survey. J Phys Ther Sci 2015;27:2687-2692.

Barber-Westin SD, Noyes FR, Galloway M. Jump-land characteristics and muscle strength development in young athletes: a gender comparison of 1140 athletes 9 to 17 years of age. Am J Sports Med 2006;34:375-384.

Blauwet C, Willick SE. The Paralympic Movement: using sports to promote health, disability rights, and social integration for athletes with disabilities. PM R 2012;4:851-856.

Bordoni B, Morabito B, Simonelli M. Ageing of the diaphragm muscle. Cureus 2020;12:e6645.

Boutellier U, Büchel R, Kundert A, Spengler C. The respiratory system as an exercise limiting factor in normal trained subjects. Eur J Appl Physiol Occup Physiol 1992;65:347-353.

Caliskan E, Pehlivan A, Erzeybek MS, Kayapinar FC, Agopyan A, Yuksel $S$, Dane S. Body mass index and percent body fat in goalball and movement education in male and female children with severe visual impairment. Neurol Psychiat Br 2011;17:39-41.

Carter AB, Kaminski TW, Douex AT Jr, Knight CA, Richards JG. Effects of high volume upper extremity plyometric training on throwing velocity and functional strength ratios of the shoulder rotators in collegiate baseball players. J Strength Cond Res 2007;21:208-215.

Cavaggioni L, Ongaro L, Zannin E, Iaia FM, Alberti G. Effects of different core exercises on respiratory parameters and abdominal strength. J Phys Ther Sci 2015;27:3249-3253.

Danneskiold-Samsøe B, Bartels EM, Bülow PM, Lund H, Stockmarr A, Holm CC, Wätjen I, Appleyard M, Bliddal H. Isokinetic and isometric muscle strength in a healthy population with special reference to age and gender. Acta Physiol (Oxf) 2009;197(Suppl 673):1-68.

Gian PG, Scarzella F, Cravero M, Tarozzo C, Beratto L. Evaluation of the effects of respiratory training on functional aerobic capacity in young soccer players. Med Sport 2019;72:477-487.

Graham BL, Steenbruggen I, Miller MR, Barjaktarevic IZ, Cooper BG, Hall GL, Hallstrand TS, Kaminsky DA, McCarthy K, McCormack MC, Oropez CE, Rosenfeld M, Stanojevic S, Swanney MP, Thompson BR. Standardization of spirometry 2019 update. An official American Thoracic Society and European Respiratory Society technical statement. Am J Respir Crit Care Med 2019;200:e70-e88.

Kim NS. Correlation between grip strength and pulmonary function and respiratory muscle strength in stroke patients over 50 years of age. J 
Exerc Rehabil 2018;14:1017-1023.

Lee K, Cho JE, Hwang DY, Lee W. Decreased respiratory muscle function is associated with impaired trunk balance among chronic stroke patients: a cross-sectional study. Tohoku J Exp Med 2018;245:79-88.

Liu X, Li P, Wang Z, Lu Y, Li N, Xiao L, Duan H, Wang Z, Li J, Shan C, $\mathrm{Wu} \mathrm{W}$. Evaluation of isokinetic muscle strength of upper limb and the relationship with pulmonary function and respiratory muscle strength in stable COPD patients. Int J Chron Obstruct Pulmon Dis 2019;14: 2027-2036.

McGuigan MR, Newton MJ, Winchester JB, Nelson AG. Relationship between isometric and dynamic strength in recreationally trained men. J Strength Cond Res 2010;24:2570-2573.

Mukaka MM. Statistics corner: a guide to appropriate use of correlation coefficient in medical research. Malawi Med J 2012;24:69-71.

Niemuth PE. The role of hip muscle weakness in lower extremity athletic injuries. Int SportMed J 2007;8:179-192.

Padkao T, Boonla O. Relationships between respiratory muscle strength, chest wall expansion, and functional capacity in healthy nonsmokers. J Exerc Rehabil 2020;16:189-196.

Peterson MD, Alvar BA, Rhea MR. The contribution of maximal force production to explosive movement among young collegiate athletes. J Strength Cond Res 2006;20:867-873.

Prieske O, Muehlbauer T, Granacher U. The role of trunk muscle strength for physical fitness and athletic performance in trained individuals: a systematic review and meta-analysis. Sports Med 2016;46:401-419.

Quanjer PH, Stanojevic S, Cole TJ, Baur X, Hall GL, Culver BH, Enright PL, Hankinson JL, Ip MS, Zheng J, Stocks J; ERS Global Lung Function Initiative. Multi-ethnic reference values for spirometry for the 3-95-yr age range: the global lung function 2012 equations. Eur Respir J 2012; 40:1324-1343.

Salinero JJ, Soriano ML, Ruiz-Vicente D, Gonzalez-Millan C, Areces F, Gallo-Salazar C, Abian-Vicen J, Lara B, Del Coso J. Respiratory function is associated to marathon race time. J Sports Med Phys Fitness 2016;56:1433-1438.

Sener U, Ucok K, Ulasli AM, Genc A, Karabacak H, Coban NF, Simsek H, Cevik H. Evaluation of health-related physical fitness parameters and association analysis with depression, anxiety, and quality of life in patients with fibromyalgia. Int J Rheum Dis 2016;19:763-772.

Shin SO, Kim NS. Upper extremity resistance exercise with elastic bands for respiratory function in children with cerebral palsy. J Phys Ther Sci 2017;29:2077-2080.

Sillanpää E, Stenroth L, Bijlsma AY, Rantanen T, McPhee JS, MadenWilkinson TM, Jones DA, Narici MV, Gapeyeva H, Pääsuke M, Barnouin Y, Hogrel JY, Butler-Browne GS, Meskers CG, Maier AB, Törmäkangas T, Sipilä S. Associations between muscle strength, spirometric pulmonary function and mobility in healthy older adults. Age (Dordr) 2014;36:9667.

Sinaki M, Nwaogwugwu NC, Phillips BE, Mokri MP. Effect of gender, age, and anthropometry on axial and appendicular muscle strength. Am J Phys Med Rehabil 2001;80:330-338.

Singer J, Yelin EH, Katz PP, Sanchez G, Iribarren C, Eisner MD, Blanc PD. Respiratory and skeletal muscle strength in chronic obstructive pulmonary disease: impact on exercise capacity and lower extremity function. J Cardiopulm Rehabil Prev 2011;31:111-119.

Son DH, Yoo JW, Cho MR, Lee YJ. Relationship between handgrip strength and pulmonary function in apparently healthy older women. J Am Geriatr Soc 2018;66:1367-1371.

Stavrou V, Vavougios G, Karetsi E, Adam G, Daniil Z, Gourgoulianis KI. Evaluation of respiratory parameters in finswimmers regarding gender, swimming style and distance. Respir Physiol Neurobiol 2018;254: 30-31.

Suchomel TJ, Nimphius S, Stone MH. The Importance of muscular strength in athletic performance. Sports Med 2016;46:1419-1449.

Tong TK, Wu S, Nie J, Baker JS, Lin H. The occurrence of core muscle fatigue during high-intensity running exercise and its limitation to performance: the role of respiratory work. J Sports Sci Med 2014;13:244251.

Tsolakis C, Simeonidis T, Georginis P, Cherouveim E, Methenitis S, Koulouvaris $\mathrm{P}$. The effect of gender, age and sports specialisation on isometric trunk strength in Greek high level young athletes. Sports Biomech 2020;7:1-15.

Ulubay G, Uyanik S, Er Dedekarginoglu B, Serifoglu I, Kupeli E, Savas Bozbas S, Sezer S, Haberal M. Peripheral muscle strength indicates respiratory function testing in renal recipients. Exp Clin Transplant 2017; 15(Suppl 1):249-253.

Wouters M, Evenhuis HM, Hilgenkamp TIM. Physical fitness of children and adolescents with moderate to severe intellectual disabilities. Disabil Rehabil 2020;42:2542-2552. 